\title{
Atividade antimicrobiana in vitro do extrato etanólico bruto da folha da Hymenaea martiana Hayne frente às Staphylococcus spp. e avaliação de seu potencial como desinfetante em cabras ${ }^{1}$
}

\author{
Dielson S. Vieira ${ }^{2 *}$, Rodolfo M. Peixoto ${ }^{3}$, Mateus M. Costa ${ }^{4}$, Davi P. Freire ${ }^{4}$, \\ Telma Maria G. Silva ${ }^{2}$ e Tania Maria S. Silva ${ }^{2}$
}

\begin{abstract}
Vieira D.S., Peixoto R.M., Costa M.M., Freire D.P., Silva T.M.G. \& Silva T.M.S. 2018. [In vitro antimicrobial activity of ethanolic extract of Hymenaea martiana Hayne leaf on strains of Staphylococcus spp. and evaluation of its potential as a disinfectant in goats.] Atividade antimicrobiana in vitro do extrato etanólico bruto da folha da Hymenaea martiana Hayne frente às Staphylococcus spp. e avaliação de seu potencial como desinfetante em cabras. Pesquisa Veterinária Brasileira 38(3):462-469. Programa de Pós-Graduação em Ciência Animal Tropical, Universidade Federal Rural de Pernambuco, Rua Dom Manoel de Medeiros s/n, Dois Irmãos, Recife, PE 52171-900, Brazil. E-mail: dielson.vieira@ig.com.br

This study aimed to evaluate the antimicrobial and antiseptic action of the crude ethanolic extract of Hymenaea martiana leaves. The study was conducted at the Laboratory of Microbiology and Immunology of UNIVASF, city of Petrolina, state o Pernambuco. The extracts were prepared using different solvents, such as absolute ethyl alcohol and distilled water. Then, Minimum Inhibitory Concentration (MIC) and Minimum Bactericidal Concentration (MBC) techniques were used. All assays were performed in triplicate. The average of MBC extract diluted in ethanol was $358 \mu \mathrm{g} / \mathrm{mL}$, and the extract diluted in distilled water was equal to $520.82 \mu \mathrm{g} / \mathrm{mL}$. There was no difference $(\mathrm{P}<0.05)$ and bacterial inhibition to extract diluted in absolute ethanol or autoclaved distilled water. Comparing the activity of the extract diluted in ethanol and the relation with the presence of blaZ gene, it was observed that the negative strains for there searched gene showed a MBC equal to $412.3 \mu \mathrm{g} / \mathrm{mL}$ in relation to those that were positive for blaZ gene, that was $308.80 \mu \mathrm{g} / \mu \mathrm{L}$, and, however, there was no statistical difference. The bacterial inhibition activity using an aqueous extract was equal for the bacteria that had or not the blaZ gene $(520.82 \mu \mathrm{g} / \mathrm{mL})$. Thus, the extract diluted in absolute ethanol in autoclaved distilled water as demonstrated antimicrobial activity, suggesting that occurred extraction of bioactive substances. Regarding the antiseptic potential, H. martiana had the same action of chlorine, although, this acted immediately, while the chlorine action happened properly an hour after the application. Both results pointed out that the crude ethanolic extract of $H$. martiana leaves has potential to combat the proliferation of environmental and infectious bacteria, emerging as a way to prevent mastitis.

INDEX TERMS: In vitro, antimicrobial, ethanolic extract, Hymenaea martiana Hayne, Staphylococcus spp., disinfectant, goats, udder cleaning, natural extract, milk quality, milking preparation, clinics.
\end{abstract}

\footnotetext{
${ }^{1}$ Recebido em 18 de abril de 2017.

Aceito para publicação em 23 de maio de 2017.

Pesquisa de Mestrado do primeiro autor.

${ }^{2}$ Universidade Federal Rural de Pernambuco (UFRPE), Câmpus Dois Irmãos, Rua Dom Manoel de Medeiros s/n, Dois Irmãos, Recife, PE 52171-900, Brasil. *Corresponding author: dielson.vieira@ig.com.br

${ }^{3}$ Instituto Federal de Educação, Ciência e Tecnologia do Sertão Pernambucano, Rodovia BR-235 Km 22, Projeto Senador Nilo Coelho-N4, Petrolina, PE 56300-000, Brasil.

${ }^{4}$ Campus Ciências Agrárias, Universidade Federal do Vale do São Francisco (Univasf), Rodovia BR-407 Km 12, Lote 543, Projeto de Irrigação Senador Nilo Coelho s/n, Petrolina, PE 56300-990, Brasil.
}

RESUMO.- Este estudo objetivou avaliar a ação antimicrobiana e antisséptica do extrato etanólico bruto da folha da Hymenaea martiana (Jatobá). O estudo foi realizado no Laboratório de Microbiologia e Imunologia da UNIVASF, na cidade de Petrolina-PE. Os extratos foram preparados utilizando diferentes diluentes, sendo estes: álcool etílico absoluto e a água destilada. Em seguida, foi empregada a técnica da Concentração Inibitória Mínima (MIC) e da Concentração Bactericida Mínima (CBM). Todos os ensaios foram realizados em triplicata. A CBM média 
do extrato diluído em etanol foi de $358 \mu \mathrm{g} / \mu \mathrm{L}$ e do extrato diluído em água destilada foi igual a $520,82 \mu \mathrm{g} / \mathrm{mL}$. Não houve diferença $(\mathrm{P}<0,05)$ quanto à inibição bacteriana para o extrato diluído em álcool etílico absoluto ou água destilada autoclavada. Ao comparar a atividade do extrato diluído em álcool etílico absoluto e a relação com a presença do gene blaZ, observou-se que os isolados negativos para o gene pesquisado apresentaram uma CBM igual a $412,3 \mu \mathrm{g} / \mathrm{mL}$, e, quando comparadas aos que foram positivos para o gene blaZ, que foi de $308,80 \mu \mathrm{g} / \mathrm{mL}$, contudo sem diferença estatística. Quanto à inibição das bactérias utilizando extrato aquoso, a atividade foi igual para as bactérias com ou sem o gene $(520,82 \mu \mathrm{g} / \mathrm{mL})$. Desse modo, tanto o extrato diluído em álcool etílico absoluto quanto em agua destilada autoclavada demonstrou atividade antimicrobiana, sugerindo que ocorreu extração de substâncias bioativas. Em relação ao potencial antisséptico, $H$. martiana teve ação pareada com o cloro, contudo aquele agiu mais rapidamente, enquanto o cloro agiu de modo ideal uma hora após a aplicação; ambos os resultados destacam que o extrato etanólico bruto das folhas de $H$. martiana possui potencial de combate à proliferação de bactérias ambientais e infecciosas, surgindo como uma forma de prevenir a mastite.

TERMOS DE INDEXAÇÃO: Antimicrobiano, in vitro, extrato etanólico bruto, Hymenaea martiana Hayne, Staphylococcus spp., desinfetante, cabras, limpeza do úbere, extrato natural, qualidade do leite, preparação da ordenha, caprinos, clínica.

\section{INTRODUÇÃO}

A mastite é uma enfermidade que acomete muitos rebanhos leiteiros, acarretando em prejuízos tanto para a saúde animal, quanto para o produtor. Possui uma vasta etiologia, e entre os agentes mais isolados, estão os microorganismos do gênero Staphylococcus (Peixoto et al. 2015), sendo também um dos principais agentes etiológicos da mastite subclínica.

Para o tratamento e prevenção desta doença, foram utilizados no decorrer dos anos produtos como antibióticos e desinfetantes, ocorrendo então a seleção de micro-organismos resistentes, o que dificulta a gestão do tratamento e da prevenção da mastite em caprinos (Bhasme et al. 2013). Um dos fatores a se observar, quando se trata de resistência a antibióticos, é a presença de genes de resistência nos micro-organismos, que por ventura podem ser expressos e impedir a ação dos produtos, e dentre eles está o gene blaZ (Palaniappan \& Holley 2010, Wendlandt et al. 2013). Uma vez ativo, este gene promove a inativação do fármaco pela enzima $\beta$-lactamase produzida por micro-organismos. Esta enzima é codificada pelo gene blaZ, que sob o sistema de classificação mais simples, possui quatro classes (A, B, C e D), neste caso uma importante defesa aos beta-lactâmicos (Chen et al. 2015).

Assim como há estudos sobre resistência aos antibióticos, as soluções sanitizantes têm sido estudadas, uma vez que podem representar um importante fator associado à prevenção de infecções. Neste caso, bons desinfetantes devem ser eficazes contra os principais patógenos da glândula mamária, ser econômicos, de fácil aplicação, e manter ou promover boas condições de higiene (Sartori et al. 2012). Devido a isto, há uma busca por alternativas aos antibióticos e desinfetantes, reduzindo o risco potencial de resíduos nos alimentos e possível promoção de patógenos resistentes, tais como o Staphylococcus aureus (Klocke et al. 2010). Desta forma, deve-se considerar a utilização dos fitoterápicos na produção animal, os quais são importantes alternativas quando se trata de prevenir e tratar doenças (Viegi et al. 2003, Mothana \& Lindequist 2005, Albuquerque et al. 2007, Peixoto et al. 2015).

A Hymenaea martiana Hayne está presente no território brasileiro e é conhecida por seu potencial medicinal. Peixoto et al. (2015) demonstraram seu potencial antimicrobiano in vitro $e$ in vivo. Outras plantas do gênero Hymenaea possuem capacidade bactericida citada por vários autores (Sá et al. 2011, Dimech et al. 2013, Aleixo et al. 2015). Diante disto, o seguinte estudo tem como objetivo avaliar a nível fitoquímico a composição do extrato etanólico bruto (EEB) da folha da Hymenaea martiana, determinar a atividade antimicrobiana deste produto frente a isolados de Staphylococcus spp. e avaliar o potencial antisséptico do EEB in vivo.

\section{MATERIAL E MÉTODOS}

O seguinte trabalho passou por avaliação do Comitê de Ética em Estudos Humanos e Animais (CEUA), da Universidade Federal do Vale do São Francisco, e foi aprovado sob o número de protocolo 0001/101214.

Utilização e produção do extrato etanólico da folha da Hymenaea martiana Hayne. As folhas foram coletadas de um exemplar, identificado como exsicata da planta 21868, que se encontra depositado no Herbário Vale do São Francisco (HVASF). A extração e produção do extrato etanólico bruto (EEB) da folha da Hymenaea martiana Hayne foi realizada de acordo com metodologia descrita por Peixoto et al. (2015), com um pequeno diferencial, após a coleta das folhas, estas passaram sete dias em estufa com circulação de ar em uma temperatura de $45^{\circ} \mathrm{C}$, para então serem maceradas e colocadas para produção do EEB.

Análise do extrato das folhas de Hymenaea martiana Hayne. Para a análise por HPLC-DAD, o extrato das folhas de Hymenaea martiana Hayne foi extraído em SPE C-18 (Extração em fase sólida). 0 cartucho foi previamente ativado utilizando $10 \mathrm{~mL}$ de metanol e $10 \mathrm{~mL}$ de água ultrapura. Cerca de $100 \mathrm{mg}$ do extrato foi solubilizado em $500 \mu \mathrm{L}$ de água acidificada ( $\mathrm{pH}=2 \mathrm{com} \mathrm{HCl}$ ) e $500 \mu \mathrm{L}$ de $\mathrm{MeOH}$. Após a aplicação do extrato no cartucho, foram adicionados $10 \mathrm{~mL}$ de água ultrapura e logo em seguida a fração com os compostos orgânicos foi eluída com $10 \mathrm{~mL}$ de metanol. Esta fração metanólica foi analisada por CLAE-DAD.

Análise por cromatografia líquida de alta eficiência, CLAEDAD. A análise foi realizada utilizando um cromatógrafo líquido de alta eficiência da Shimadzu Prominence LC-20AT com um detector de arranjo de diodo (SPDM20), injetor automático SIL-20AC, forno CTO-20A e degaseificador DGU-20A5. A separação cromatográfica foi feita com uma coluna Luna C-18 $(250 \mathrm{~mm} \times 4,6 \mathrm{~mm} \times 5 \mu \mathrm{m}$, Phenomenex).

Foi utilizada como fase móvel a mistura de $\mathrm{H}_{2} \mathrm{O}$ : ácido fórmico (99:1, Solvente A) e metanol (Solvente B), com sistema de eluição: 0-10min, $90-100 \%$ de B, $10-30 \mathrm{~min}, 100 \%$ de B fluxo de $1,0 \mathrm{~mL} /$ minuto, 
temperatura de $35^{\circ} \mathrm{C}$ e para monitoramento foi utilizado o comprimento de onda de $320 \mathrm{~nm}$. Para a filtração das amostras foram utilizados filtros de nylon (Whatman) $0,45 \mu \mathrm{m}$. Todos os solventes utilizados foram grau HPLC.

Determinação da atividade antibacteriana. Neste estudo foram utilizados 22 isolados de Staphylococcus sp., sendo 18 obtidos de casos de mastite subclínica, no estado de Pernambuco ( 9 apresentando gene blaZ e 9 com ausência deste gene), e três cepas de ATCC $(25923,6538,12228)$ e um isolado clínico MRSA de origem humana. A concentração bactericida mínima (CBM) foi realizada seguindo o padrão do documento M7-A7 (CLSI 2012). Os extratos foram diluídos em dois diluentes, álcool etílico absoluto (AEA) e agua destilada autoclavada (ADA), após diluição dos extratos a concentração de $25 \mathrm{mg} / \mathrm{ml}$, seguiu-se a metodologia com a preparação do inóculo, em uma suspensão bacteriana com turvação equivalente a 0,5 da escala de Mac Farland. 0 material então foi levado à estufa a $37^{\circ} \mathrm{C} / 24 \mathrm{~h}$, em condições de aerobiose e na sequência realizou-se a CBM, semeando o material líquido em Ágar Muller Hinton e devolvendo a estufa a $37^{\circ} \mathrm{C} / 24 \mathrm{~h}$, sendo considerada eficaz a menor concentração do extrato em estudo com potencial bactericida frente às cepas do micro-organismo. Os ensaios foram realizados em triplicata, e no estudo utilizando álcool absoluto, foi realizado o controle deste produto.

Desinfecção de animais naturalmente infectados com Staphylococcus spp. Foram utilizadas 10 fêmeas caprinas da raça Saanen, com faixa etária variando entre 2 e 5 anos, entre segunda e terceira lactação. No total, fez-se a desinfecção em 20 metades mamárias. Os animais foram avaliados clinicamente (frequência cardíaca e respiratória, temperatura retal e superficial, avaliação das mucosas e da hidratação) demonstrando estarem aptos ao estudo. Os animais foram negativos em três lactoculturas consecutivas, sendo adotado um intervalo de sete dias entre estas coletas.

Os animais foram submetidos ao pré-dipping (30 segundos de imersão), utilizando duas formas, como segue abaixo:

Grupo 01 (5 animais): imersão em solução de extrato hidrossolúvel da Hymenaea martiana Hayne, na concentração de 5\% seguido da secagem com papel toalha descartável (estéril).

Grupo 02 (5 animais): imersão em solução a base de Hipoclorito Agrisept ${ }^{\circledR}$ MC Tabs (1400ppm de hipoclorito) e secagem com papel toalha descartável (estéril).

Em cada tratamento a análise da população da microbiota das metades mamárias foi realizada nos tempos um minuto, 30 minutos e uma hora, além de uma amostra controle.

A coleta dos espécimes clínicos para o isolamento e quantificação das UFC $/ \mathrm{cm}^{2}$ de cada teto foi obtido com "swab" bacteriológico estéril e molde de papel cartolina estéril com abertura central de $2 \mathrm{~cm}$ por $2 \mathrm{~cm}$. Para coleta, foram realizados quatro movimentos cruzados sobre uma área de $2 \mathrm{~cm}^{2}$ na região mediana do teto evitando a região proximal do esfíncter mamário. 0 "swab" foi acondicionado e encaminhado para posteriores análises.

Contagem e isolamento bacteriano. Após o processo citado no tópico anterior, os "swabs" foram vertidos em $5 \mathrm{~mL}$ de Agua Peptonada Tamponada e transportados ao laboratório e então realizou-se as diluições decimais sucessivas até $10^{-4} \mathrm{em} 9 \mathrm{~mL}$ de caldo Muller-Hinton. Posteriormente, foram plaqueados $1 \mathrm{~mL}$ das amostras diluídas em placas de Petri estéreis e adicionado o meio de Contagem Padrão em Placa (PCA). Após homogeneização (pour plate), as placas foram incubadas em estufa a $37^{\circ} \mathrm{C}$ por 48 horas, quando então foram contadas as unidades formadoras de colônias (UFC) bacterianas para determinação da quantidade de micro-organismos totais no teto, avaliando a eficácia e acurácia das técnicas utilizadas. Para o isolamento, o "swab" foi semeado em meio ágar sangue ovino a 8\%, e a caracterização fenotípica dos agentes foi realizada de acordo com Koneman et al. (2008).

Análise dos dados. Foi realizada a técnica de estatística descritiva por meio da distribuição das frequências relativa e absoluta para os achados microbiológicos. A ausência de normalidade dos dados foi confirmada pelo teste de Shapiro-Wilk. Dessa forma, os valores obtidos para UFC $/ \mathrm{cm}^{2}$ foram submetidos à transformação logarítmica de base $10\left(\log _{10}\right)$ para análise estatística, e a função antilogarítmica para apresentação dos resultados. Os valores obtidos de UFC $/ \mathrm{cm}^{2}$ foram comparados entre os grupos (H. martiana e hipoclorito), utilizando-se o teste $\mathrm{T}$ para amostras independentes e entre os tempos experimentais pela análise de variância para medidas repetidas, usando o teste de Bonferroni para comparação de médias. Para análise dos dados, foi utilizado o programa Statistical Package for the Social Sciences (SPSS) versão 20.0 para Windows.

\section{RESULTADOS}

\section{Análise fitoquímica}

A análise do cromatograma HPLC-DAD (Fig.1) permitiu sugerir que os principais picos presentes na amostra podem ser fenólicos do tipo flavonoides, apresentando comprimentos de onda máximos em torno de $313 \mathrm{~nm}$. Para a identificação dos compostos serão necessárias outras análises como LC-MS.

\section{Atividade antimicrobiana in vitro}

Quanto à atividade antimicrobiana do extrato etanólico bruto (EEB) da folha da Hymenaea martiana Hayne, os valores não diferiram estatisticamente, demonstrando que os dois diluentes podem ser utilizados em trabalhos preventivos e terapêuticos para animais.

Dos 22 isolados utilizados, 50\% (11/22) dos isolados que foram desafiados com o extrato diluído em água destilada autoclavada (ADA), tiveram sua CBM em 781,25 $\mu \mathrm{g} / \mathrm{mL}$. Em relação ao AEA a CBM foi de $390,6 \mu \mathrm{g} / \mathrm{mL}(11 / 22)$ para $50 \%$ dos isolados, seguidos de 40,9\% (9/22) dos isolados neste mesmo diluente. Quanto à variação da CBM entre os diluentes, $22,7 \%$ apresentaram os mesmos valores em ambos diluentes, e 5/22 tiveram melhor resultado quando desafiados com o extrato diluído em ADA. A CBM média do extrato diluído em etanol foi de $358 \mu \mathrm{g} / \mathrm{mL}$ e do extrato

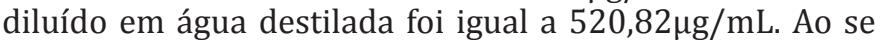
comparar a atividade do extrato diluído em etanol e a relação com a presença do gene blaZ, observou-se que os isolados negativos para o gene pesquisado apresentaram uma CBM igual a $412,3 \mu \mathrm{g} / \mathrm{mL}$, quando comparou-se com aqueles que foram positivos para o gene blaZ $(308,80 \mu \mathrm{g} / \mathrm{mL})$, contudo sem diferença estatística. Quanto à inibição das bactérias utilizando extrato aquoso, a atividade foi igual para as bactérias com ou sem os genes $(520,82 \mu \mathrm{g} / \mathrm{mL})$.

Como é possível observar na Figura 2 a presença ou ausência do gene blaZ, não é fator determinante e nem foi observada $(\mathrm{P}<0,05)$ atividade do EEB frente às cepas de Staphylococcus sp. Em relação à ausência do gene blaZ, na Figura 2A, a CBM do EBB diluído em etanol foi de 390,6 $\mu \mathrm{g} / \mathrm{mL}$ $78 \%$ (7/9), já quando diluído em ADA aproximadamente $45 \%$ dos isolados tiveram sua CBM em 781,25 $\mu \mathrm{g} / \mathrm{mL}$ (4/9), 33\% com $195,3 \mu \mathrm{g} / \mathrm{mL}$ e $22 \%$ com 390,6 $\mu \mathrm{g} / \mathrm{mL}$. Já na imagem $2 \mathrm{~B}$, a CBM do EEB diluído em etanol foi $195,3 \mu \mathrm{g} / \mathrm{mL}$ em $67 \%$ 

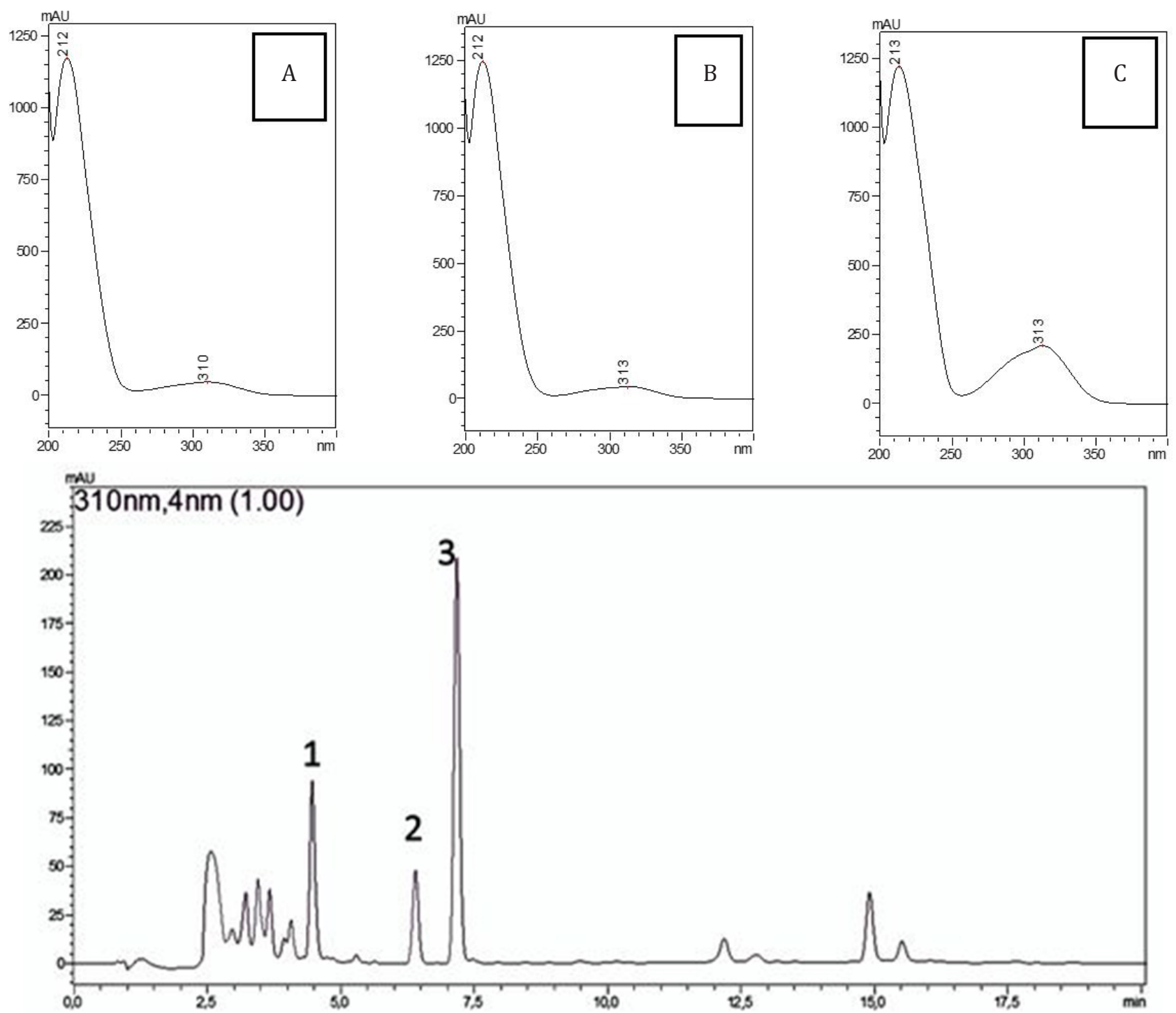

Fig.1. Cromatograma (HPLC-DAD em 310nm) do extrato etanólico bruto obtido das folhas de Hymenaea martiana Hayne. Em (A-C) constam três tipos de flavonoides que foram encontrado por HPLC-DAD, porém para sua identificação necessitam-se de maiores análises.

(6/9) dos isolados, e ao diluir em ADA, a CBM de 45\% (4/9) dos isolados foi de $781,25 \mu \mathrm{g} / \mathrm{mL}$, assim como $33 \%$ das cepas com $390,6 \mu \mathrm{g} / \mathrm{mL}$ e $22 \%$ com $195,3 \mu \mathrm{g} / \mathrm{mL}$.

\section{Atividade antimicrobiana in vivo}

Foram testadas duas soluções, a comercial (Agrisept ${ }^{\circledR}$ MC Tabs) que possui $1.400 \mathrm{ppm}$ de hipoclorito, e uma solução com $5 \%$ do EEB da folha da Hymenaea martiana Hayne. Não foi observada diferença estatística $(\mathrm{P}<0,05)$ entre os tratamentos, quanto a sua capacidade bactericida. Porém observou-se que a H. martiana Hayne agiu prontamente assim que foi colocada em contato com a pele do teto, diferente do produto comercial que agiu no seu potencial máximo apenas uma hora após a imersão $(\mathrm{P}<0,05)$. No Quadro 1, é possível observar que o extrato etanólico bruto da H. martiana Hayne tem potencial como produto bactericida devido a sua atividade demonstrada no seguinte quadro.

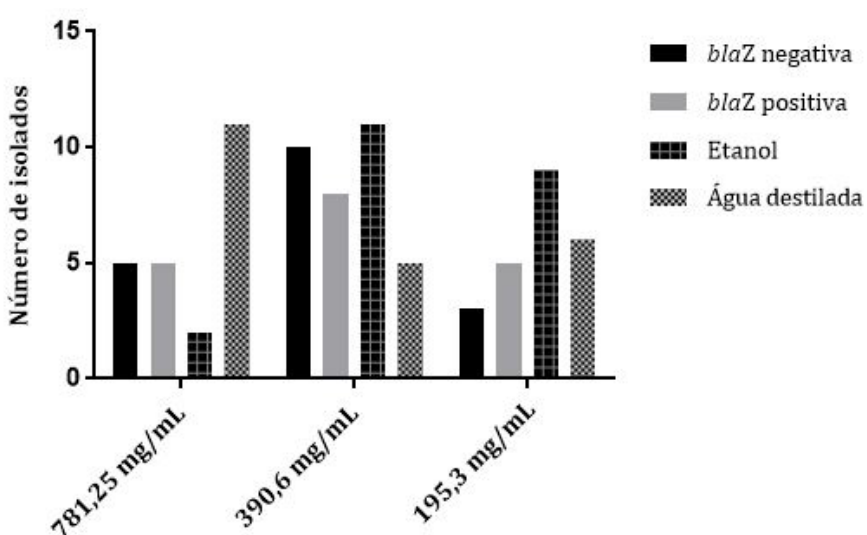

Fig.2. Comparação da concentração bactericida mínima entre isolados blaZ positivo e blaZ negativo e dois diluentes utilizados no EEB da Hymenaea martiana. 
Quadro 1. Médias obtidas para UFC/ $\mathrm{cm}^{2}$ nos diferentes tempos experimentais em cabras tratadas com duas soluções diferentes, 2016

\begin{tabular}{ccccc}
\hline & $\mathrm{T} 0$ & $\mathrm{~T} 1$ & $\mathrm{~T} 2$ & $\mathrm{~T} 3$ \\
\hline Hymenaea martiana & $16 \times 10^{3 \mathrm{Aa}}$ & $2,3 \times 10^{3 \mathrm{Ab}}$ & $2,1 \times 10^{3 \mathrm{Ab}}$ & $4,4 \times 10^{2 \mathrm{Aab}}$ \\
Hipoclorito & $9,7 \times 10^{3 \mathrm{Aa}}$ & $4,7 \times 10^{2 \mathrm{Aab}}$ & $1,6 \times 10^{3 \mathrm{Ab}}$ & $2,3 \times 10^{3 \mathrm{Ab}}$
\end{tabular}

Para cada momento, valores seguidos por letras maiúsculas iguais não diferem entre si ( $\mathrm{P}>0,05)$; Para cada grupo, valores seguidos por letras minúsculas iguais não diferem entre si (P > 0,05); T0- tempo sem imersão (controle), T1- UFC/ $\mathrm{cm}^{2}$ após um minuto de ocorrida a imersão; T2- UFC/cm² após 30 minutos de ocorrida a imersão e T3- UFC/ $\mathrm{cm}^{2}$ após uma hora de ocorrida a imersão.

\section{DISCUSSÃO}

\section{Análise fitoquímica}

De acordo com a avaliação fitoquímica do extrato etanólico bruto (EEB) da folha da Hymenaea martiana Hayne, obteve-se a informação da dominância de três tipos flavonoides, que precisam de melhores análises por técnicas mais apuradas para sua identificação. Dimech et al. (2013), também encontraram os flavonoides como componentes principais ao avaliar a Hymenaea stigonocarpa Mart. ex. Hayne, e Silva et al. (2012) relatam a dominância do flavonoide astilbina como o principal composto fenólico presente na H. coubaril. Os flavonoides são metabólitos secundários de baixo peso molecular, amplamente distribuídos no reino vegetal, com várias atividades biológicas (Hernandez et al. 2000), que de acordo com Mishra \& Tiwari (2011), apresentam destaque como produto terapêutico, além disso estes autores afirmam que as áreas de doenças infecciosas e oncologia se beneficiaram dessas numerosas classes de drogas, capazes de interagir com muitas áreas dentro das células, e de fato têm sido fundamentais na descoberta e desenvolvimento de medicamentos. Assim como, relataram a atividade antimicrobiana de extratos brutos que possuem flavonoides em sua composição, frente a estirpes de $S$. aureus (Chattopadhyay et al. 2001, Cushnie \& Lamb 2011). Além disso, Peixoto et al. (2015), ao explorar o EEB feito com a casca da Hymenaea martiana Hayne, observou também a presença deste composto, com potencial bactericida.

\section{Atividade antimicrobiana in vitro}

0 EEB da folha da Hymenaea martiana Hayne teve sua ação bactericida avaliada in vitro, observando-se atividade frente a isolados de $S$. aureus e $S$. epidermidis, bactérias Gram positivas comumente causadoras de mastite caprina. Os produtos naturais têm melhor ação sobre as bactérias gram positivas, podendo atuar de modo diferenciado nos micro-organismos (Palaniappan \& Holley 2010, Sá et al. 2011). No presente estudo $50 \%(11 / 22)$ dos isolados apresentaram valor de CBM chegando até $781,25 \mu \mathrm{g} / \mathrm{mL}$ quando diluídos em água destilada autoclavada. Já quando a diluição foi realizada com etanol, a CBM foi de 390,6 $\mu \mathrm{g} / \mathrm{mL}(11 / 22)$. Garcia et al. (2011) ao estudar o extrato hidroalcóolico da $H$. coubaril frente a S. aureus obteve $98 \%$ de atividade da CBM em $53,25 \mu \mathrm{g} / \mathrm{mL}$, assim como este trabalho demonstrando o potencial das plantas do gênero Hymenaea.

Neste estudo não houve diferença $(\mathrm{P}<0,05)$ quanto ao diluente utilizado. Contudo, alguns grupos obtiveram melhor atividade ao diluir em etanol seus extratos (Schnitzler et al. 2008, Kannaiyan et al. 2012, Peixoto et al. 2015). 0 diluente pode não ser fator determinante na ação do extrato. Sá et al. (2011), obtiveram menor atividade bactericida ao desafiar S. aureus com o extrato etanólico da H. coubaril e Aleixo et al.
(2015) ao utilizar o extrato hidroetanólico. 0 uso do etanol na sanitização da glândula mamária pode causar um ressecamento, em que causa danos à pele do teto e pode deixar resíduos, sendo mais indicada a utilização do extrato diluído em água, levando em consideração também a relação custo e benefício para o produtor. Ao se utilizar a água como diluente, evoca-se um sentido de sustentabilidade na utilização do medicamento (Varo et al. 2017). Em estudos como o de Hendrychová et al. (2014) o extrato aquoso não afetou no potencial antioxidante de plantas do gênero Bergenia.

Várias frações foram testadas do extrato da casca da Hymenaea Stigonocarpa Mart. ex. Hayne por Dimech et al. (2013), em que os valores de atividade antimicrobiana estiveram entre 64 e $512 \mu \mathrm{g} / \mathrm{mL}$, o que se aproxima do presente trabalho onde foram obtidos valores de 195,3 até $781,25 \mu \mathrm{g} / \mathrm{mL}$ ao se utilizar uma planta do mesmo gênero. Justifica esta atividade frente a isolados de S. aureus, a grande variedade de compostos fenólicos, além da presença dos flavonoides no extrato (Dimech et al. 2013).

Estudos têm descrito que os Staphylococcus spp. possuem vários fatores de resistência, dentre eles a presença do gene blaZ, sendo caracterizados como resistentes aos beta-lactâmicos (Bush \& Jacoby 2010, Chen et al. 2015). Esta resistência justifica a busca por compostos alternativos que atuem tanto sobre formas multi-resistentes, como sensíveis de Staphylococcus spp. (Garcia et al. 2011). Neste estudo, não se observou diferença na atividade antimicrobiana do extrato de H. martiana Hayne frente a isolados que possuíam ou não o gene blaZ. Dessa forma, isto pode ser considerado um fator positivo quando se discute a ação dos produtos naturais em bactérias Gram positivas. Dimech et al. (2013) ao utilizarem o extrato hidroalcoólico da casca do caule da Hymenaea Stigonocarpa Mart. ex. Hayne em S. aureus relataram que o extrato gerou vários processos na cepa utilizada, dentre eles falhas ao inserir peptideoglicanos na membrana externa, falha na pressão osmótica interna, devido à ação de produtos na membrana externa, alterações nos componentes intracelulares, tais como ácidos nucleicos e proteínas (Dimech et al. 2013).

As cepas utilizadas neste trabalho tiveram do extrato diluído em meio aquoso a CBM variando de 195 até $781 \mu \mathrm{g} / \mathrm{mL}$, neste caso ocorrendo uma atividade bactericida com valores também crescentes indo de 195 até $390,6 \mu \mathrm{g} / \mathrm{mL}$ em cerca de $50 \%$ dos isolados, assim como a outra metade (11/22) obteve ação moderada $(781,25 \mu \mathrm{g} / \mathrm{mL})$. Estes valores se apresentam dentro dos padrões descritos por Sartoratto et al. (2004) em que estes destacam que os agentes de ação forte terão intervalo de $50-500 \mu \mathrm{g} / \mathrm{mL}$ de CBM, já quando forem de ação moderada serão obtidos valores de CBM de 600 até $1500 \mu \mathrm{g} / \mathrm{mL}$. A partir destes dados, ressalta-se o grande potencial de utilização das plantas do gênero Hymenaea como base para produtos antimicrobianos. 


\section{Atividade antimicrobiana in vivo}

Quando comparados os dados referentes ao tratamento dos animais entre os grupos experimentais (1400ppm de hipoclorito x EEB da folha da H. martiana Hayne), não foram observadas diferenças estatísticas em nenhum dos momentos experimentais. Ao se observar a atividade do EEB da folha da H. martiana diluída a 5\%, um potencial como antisséptico foi evidenciado, pois agiu de modo rápido, um minuto após a imersão. Faz- se necessários produtos de ação imediata, pois na rotina da ordenha o tempo é um fator que pode interferir na coleta e armazenamento do leite, devido ao fato do óstio de liberação do leite ficar acessível por até duas horas (Langoni 2013). 0 esfíncter do teto e o canal do teto são importantes barreiras primárias contra a invasão dos patógenos presentes no úbere, assim é essencial que tais estruturas estejam em condições físicas e de higiene perfeitas para prevenir a infecção intramamária (Manzi et al. 2012).

O objetivo da rotina de higiene do teto não é apenas para reduzir risco de infecção de mastite, mas também para melhorar a qualidade do leite (Gleeson et al. 2009). A redução da atividade bacteriana está descrita no Quadro 1. Neste caso, o cloro após a imersão obteve uma redução nas contagens bacterianas de $95 \%$ e a $H$. martiana de $86 \%$. Gleeson et al. (2009), obtiveram uma redução de $30 \%$ ao utilizar o cloro como desinfetante pré ordenha. A realização do pré-dipping reduz em $50 \%$ a incidência de ocorrer mastite causada por patógenos ambientais (Oliver et al. 1993). Sendo que no presente trabalho a redução foi em média de $80 \%$. Assim o pré-dipping é uma importante ferramenta para controle dos patógenos causadores da mastite em rebanhos leiteiros, e assim ser fundamental na prevenção de doenças de origem ambiental e infecciosa (Gibson et al. 2008, Gleeson et al. 2009, Kamal \& Bayoumi 2015).

0 cloro e a $H$. martiana agiram com uma hora após a imersão dos tetos, mantendo a redução de UFC $/ \mathrm{cm}^{2}$ de $98 \%$ e $89 \%$ respectivamente. Fator muito importante, já que o óstio de saída do leite fica aberto durante este tempo, ajudando na prevenção da mastite pós-ordenha (Langoni 2013). 0 tempo de ação dos produtos deve ser compatível ao manejo que os animais são submetidos e não devem possuir efeito colateral sobre a pele do animal e muito menos deixar resíduos no leite (Gleeson et al. 2009, Langoni 2013).

A atividade do extrato utilizado como sanitizante é importante, pois reforça a capacidade de utilização dos produtos naturais pela população, alguns autores justificam este potencial afirmando que há uma complexidade de compostos presentes em um extrato de planta, favorecendo sua utilização na produção animal (Mishra \& Tiwari 2011, Cipriano et al. 2014, Peixoto et al. 2015). Thoria et al. (2011), reportam que mais estudos, bioquímicos e intrínsecos por exemplo, devem ser realizados devido ao formato mesclado dos extratos de plantas. Dimech et al. (2013) encontraram alterações a nível de DNA em S. aureus desafiadas com Hymenaea Stigonocarpa Mart. Ex Hayne. Assim como o sinergismo entre antimicrobianos, conseguiu produzir em cepas MRSA alteração na síntese da parede celular, neste caso, a junção de produtos de modo controlado pode afetar a sobrevivência e patogenia do Staphylococcus spp. (Gonzales et al. 2015).

0 cloro tem eficácia comprovada, tanto na rotina prática como em estudos laboratoriais (Magnusson et al. 2006, Gibson et al. 2008, Jaenisch et al. 2010). Porém este não foi tão efetivo quando utilizado frente a leveduras, e na presença de 10\% de matéria orgânica (Coutinho et al. 2012). Em relação ao S. aureus, o cloro foi eficaz em estudos in vitro, na concentração de 1\%. 0 melhor efeito do cloro na desinfecção da pele do teto pode não estar relacionado a seus princípios ativos, e sim a forma como os procedimentos de aplicação são realizados (Magnusson et al. 2006, Gibson et al. 2008). Porém sua utilização deve ser limitada, pois de acordo com a WHO (2008), é um produto que pode gerar nos micro-organismos o desenvolvimento da resistência.

O hipoclorito, assim como os produtos à base de iodo e clorexidina, são comumente indicados como sanitizantes na prevenção da mastite, contudo estes produtos têm atividade diminuída na presença de material biológico e desencadeiam a seleção de micro-organismos resistentes, não sendo então uma alternativa nestes casos (Gibson et al. 2008, Jaenisch et al. 2010, Coutinho et al. 2012). Isto reforça o potencial alternativo a ser explorado dos produtos naturais, com a finalidade de profilaxia da mastite caprina.

A redução da log do AGRISEPT ${ }^{\circledR}$ foi de 3 log, resultados melhores do que os obtidos por Kamal \& Bayoumi (2015), que obtiveram uma redução de $1 \mathrm{log}$, destacando mesmo assim a importância do pré-dipping na diminuição de patógenos ambientais presentes no teto. A ação de realizar a desinfecção dos animais promove uma diminuição dos mesófilos aeróbicos no teto, diminuindo consequentemente as chances de contaminação do leite e dos tanques de armazenamento (Elmoslemany et al. 2010, Bava et al. 2011). A higiene do úbere é importante porque influencia na qualidade do leite e é relacionada a ocorrência de patógenos, especialmente os ambientais (Manzi et al. 2012).

Um grande desafio para a indústria de laticínios é a necessidade de se reduzir o uso de compostos antimicrobianos em animais produtores de alimentos (Mukherjee et al. 2010). Assim, a utilização de fitoterápicos demonstra-se com capacidade de diminuir a população bacteriana no teto, como foi observado nesta pesquisa.

\section{CONCLUSÕES}

O extrato etanólico bruto da folha da Hymenaea martiana Hayne possui como constituinte dominante os flavonoides. Quando avaliado in vitro não houve diferença estatísticas quanto a atividade antimicrobiana da H. martiana Hayne, em relação ao diluente utilizado.

Os isolados possuírem ou não o gene blaZ, não foi significativo na atividade bactericida do fitoterápico.

Com relação ao estudo in vivo, o extrato aquoso da H. martiana Hayne tem potencial como desinfetante, mostrando que o fitoterápico pode ser uma alternativa na prevenção da mastite caprina.

Agradecimentos.- Coordenação de Aperfeiçoamento de Pessoal do Ensino Superior (CAPES).

\section{REFERÊNCIAS}

Albuquerque U.P., Monteiro J.M., Ramos M.A. \& Amorim E.L. 2007. Medicinal and magic plants from a public market in northeastern. Brazil. J. Ethnopharmacol. 110(1):76-91. http://dx.doi.org/10.1016/j.jep.2006.09.010. PMid:17056216.

Aleixo A.A., Camargos V.N., Herrera K.M.S., Andrade A.C.S.P., Santos M., Miranda V.C., Carvalho R.S., Magalhães J.T., Magalhães J.C., Lima L.A.R.S. 
\& Ferreira J.M.S. 2015. Synergistic activity from Hymenaea courbaril L. and Stryphnodendron adstringens (Mart.) Coville against multidrugresistant bacteria strains. J. Med. Plants Res. 9(26):741-748. http://dx.doi. org/10.5897/JMPR2014.5502.

Bava L., Zucali M., Sandrucci A., Brasca M., Vanoni L., Zanini L. \& Tamburini A. 2011. Effect of cleaning procedure and hygienic condition of milking equipment on bacterial count of bulk tank milk. J. Dairy Res. 78(2):211219. http://dx.doi.org/10.1017/S002202991100001X. PMid:21371358.

Bhasme P.C., Kurjogi M.M., Sanakal R.D., Kaliwal R.B. \& Kaliwal B.B. 2013. In silico characterization of putative drug targets in Staphylococcus saprophyticus, causing bovine mastitis. Bioinformation 9(7):339-344. http://dx.doi.org/10.6026/97320630009339. PMid:23750077.

Bush K. \& Jacoby G.A. 2010. Updated functional classification of b-lactamases. Antimicrob. Agents Chemother. 54(3):969-976. http://dx.doi.org/10.1128/ AAC.01009-09. PMid:19995920.

Chattopadhyay D., Maiti K., Kundu A.P., Chakraborty M.S., Bhadra R., Mandal S.C. \& Mandal A.B. 2001. Antimicrobial activity of Alstonia macrophylla: a folklore of bay islands. J. Ethnopharmacol. 77(1):49-55. http://dx.doi. org/10.1016/S0378-8741(01)00264-1. PMid:11483378.

Chen M.M.S., Boardman W.S.J., Smith I., Goodman A.E. \& Brown M.H. 2015 Characterisation of $\beta$-lactam resistance mediated by blaZ in staphtlococci recovered from captive and fre-ranging wallabies. J. Glob. Antimicrob. Resist. 3(3):184-189. http://dx.doi.org/10.1016/j.jgar.2015.05.002. PMid:27873707.

Cipriano J., Martins L., Deus M.S.M. \& Peron A.P. 2014. 0 gênero Hymenaea e suas espécies mais importantes do ponto de vista econômico e medicinal para o Brasil. Caderno De Pesquisa. Biologia 26(2):41-51.

CLSI 2012. Institute methods for dilution antimicrobial susceptibility tests for bacteria that grow aerobically. 8th ed. Approved Standard, M07-A8, CLSI, Wayne, PA, USA.

Coutinho L.C.A., Medeiros E.S., Silveira N.S.S., Silva L.B.G. \& Mota R.A. 2012. Eficácia in vitro de desinfetantes utilizados na anti-sepsia dos tetos frente a leveduras isoladas do leite de vaca com mastite. Pesq. Vet. Bras. 32(1):6165. http://dx.doi.org/10.1590/S0100-736X2012000100010.

Cushnie T.P.T. \& Lamb A.J. 2011. Recent advances in understanding the antibacterial properties of flavonoids. Int. J. Antimicrob. Agents 38(2):99107. http://dx.doi.org/10.1016/j.ijantimicag.2011.02.014. PMid:21514796.

Dimech G.S., Soares L.A., Ferreira M.A., de Oliveira A.G., Carvalho Mda.C. \& Ximenes E.A. 2013. Phytochemical and antibacterial investigations of the extracts and fractions from the stem bark of Hymenaea Stigonocarpa Mart. ex. Hayne and effect on ultrastructure of Staphylococcus Aureus induced by hydroalcoholic extract. Sci. World J. 2013:862763. http:// dx.doi.org/10.1155/2013/862763. PMid:24396311.

Elmoslemany A.M., Keefe G.P., Dohoo I.R., Wichtel J.J., Stryhn H. \& Dingwell R.T. 2010. The association between bulk tank milk analysis for raw milk quality and on-farm management practices. Prev. Vet. Med. 95(1/2):32-40. http://dx.doi.org/10.1016/j.prevetmed.2010.03.007. PMid:20381889.

Garcia C.S., Ueda S.M.Y. \& Mimica L.M.J. 2011. Avaliação da atividade antibacteriana in vitro de extratos hidroetanólicos de plantas sobre Staphylococcus aureus MRSA e MSSA. Revta Inst. Adolfo Lutz Sao Paulo 70(4):589-598.

Gibson H., Sinclair L.A., Brizuela C.M., Worton H.L. \& Protheroe R.G. 2008. Effectiveness of selected pre-milking teat-cleaning regimes in reducing teat microbial load on commercial dairy farms. Lett. Appl. Microbiol. 46(3):295-300. http://dx.doi.org/10.1111/j.1472-765X.2007.02308.x. PMid:18179447.

Gleeson D., O'Brien B., Flynn J., O' Callaghan E. \& Galli F. 2009. Effect of pre-milking teat preparation procedures on the microbial count on teats prior to cluster application. Ir. Vet. J. 62(7):461-467. http://dx.doi. org/10.1186/2046-0481-62-7-461. PMid:21851738.
Gonzales P.R., Pesesky M.W., Bouley R., Ballard A., Biddy B.A., Suckow M.A., Wolter W.R., Schroeder V.A., Burnham C.D., Mobashery S., Chang M. \& Dantas G. 2015. Synergistic, collaterally sensitive $\beta$-lactam combinations suppress resistance in Mrsa. Nat. Chem. Biol. 11(11):855-861. http:// dx.doi.org/10.1038/nchembio.1911. PMid:26368589.

Hendrychová H., Vildova A., Kocevar-Glavac N., Tumova L., Kanybekovna E.A. \& Tuma J. 2014. Antioxidant activity and phenolic content of Bergenia crassifolia: B. x ornata and B. ciliata. Nat. Prod. Commun. 9(4):519-522. PMid:24868873.

Hernández N.E., Tereschuk M.L. \& Abdala L.R. 2000. Antimicrobial activity of flavonoids in medicinal plants from Tafí del Valle (Tucumán, Argentina). J. Ethnopharmacol. 73(1/2):317-322. http://dx.doi.org/10.1016/S03788741(00)00295-6. PMid:11025172.

Jaenisch F.R.F., Kuchiishi S.S. \& Coldebella A. 2010. Atividade antibacteriana de desinfetantes para uso na produção orgânica de aves. Ciência Rural 40(2):354-358. http://dx.doi.org/10.1590/S0103-84782010000200020.

Kamal R.M. \& Bayoumi M.A. 2015. Efficacy of premilking and postmilking teat dipping as a control of subclinical mastitis in Egyptian dairy cattle. Int. Food Res. J. 22(3):1037-1042.

Kannaiyan M., Manuel V.N., Raja V., Thambidurai P., Mickymaray S. \& Nooruddin T. 2012. Antimicrobial activity of the ethanolic and aqueous extracts of Salacia chinensis Linn. against human pathogens. Asian Pac. J. Trop. Dis. 2(Suppl.1):S416-S420. http://dx.doi.org/10.1016/S2222-1808(12)60194-7.

Klocke P., Ivemeyer S., Butler G., Maeschli A. \& Heil F. 2010. A randomized controlled trial to compare the use of homeopathy and internal Teat Sealers for the prevention of mastitis in organically farmed dairy cows during the dry period and 100 days post-calving. Homeopathy 99(2):90-98. http:// dx.doi.org/10.1016/j.homp.2009.12.001. PMid:20471611.

Koneman E.W., Allen S.D., Janda W.M., Schreckenberger P.C., Winn JR W.C., Janda, W. 2008. Diagnóstico microbiológico. 6th ed. Guanabara Koogan, Rio de Janeiro. 1565p.

Langoni H. 2013. Qualidade do leite: utopia sem um programa sério de monitoramento da ocorrência de mastite bovina. Pesq. Vet. Bras. 33(5):620626. http://dx.doi.org/10.1590/S0100-736X2013000500012.

Magnusson M., Christiansson A., Svensson B. \& Kolstrup C. 2006. Effect of different premilking manual teat-cleaning methods on bacterial spores in milk. J. Dairy Sci. 89(10):3866-3875. http://dx.doi.org/10.3168/jds. S0022-0302(06)72429-8. PMid:16960062.

Mishra B.B. \& Tiwari V.K. 2011. Natural products: an evolving role in future drug discovery. Eur. J. Med. Chem. 46(10):4769-4807. http://dx.doi. org/10.1016/j.ejmech.2011.07.057. PMid:21889825.

Mothana R.A.A. \& Lindequist U. 2005. Antimicrobial activity of some medicinal plants of the island Soqotra. J. Ethnopharmacol. 96(1/2):177-181. http:// dx.doi.org/10.1016/j.jep.2004.09.006. PMid:15588668.

Mukherjee R., De U.K. \& Ram G.C. 2010. Evalution of mammary gland immunity and therapeutic potential of Tinospora cordifolia against bovine subclinical mastitis. Trop. Anim. Health Prod. 42(4):645-651. http://dx.doi. org/10.1007/s11250-009-9471-z. PMid:19876755.

Oliver S.P., Lewis M.J., Ingle T.L., Gillespie B.E., Matthews K.R. \& Dowlen H.H. 1993. Premilking teat disinfection for the preservation of environmental pathogen intramammary infections. J. Food Prot. 56(10):852-855. http:// dx.doi.org/10.4315/0362-028X-56.10.852.

Palaniappan K. \& Holley R.A. 2010. Use of natural antimicrobials to increase antibiotic susceptibility of drug resistant bactéria. Int. J. Food Microbiol. 140(2/3):164-168. http://dx.doi.org/10.1016/j.ijfoodmicro.2010.04.001. PMid:20457472.

Peixoto R.M., Araújo R.M.P., Peixoto L.J.S., Bomfim S.A.G., Silva T.M.G., Silva T.M.S., Almeida J.R.G.S., Mota R.A. \& Costa M.M. 2015. Treatment of goat mastitis experimentally induced by Staphylococcus Aureus: a formulation containing Hymenaea Martiana extract. Small Rumin. Res. 130:229-235. 
Manzi M.P., Nóbrega D.B., Faccioli P.Y., Troncarelli M.Z., Menozzi B.D. \& Langoni H. 2012. Relationship between teat-end condition, udder cleanliness and bovine subclinical mastitis. Res. Vet. Sci. 93(1):430-434. http://dx.doi. org/10.1016/j.rvsc.2011.05.010. PMid:21669449.

Sá M.C.A., Peixoto R.M., Krewer C.C., Almeida J.R.G., Vargas A.C. \& Costa M.M. 2011. Antimicrobial activity of caatinga biome ethanolic plant extracts against gram negative and positive bactéria. Revta Bras. Ciênc. Vet., Heredia, 18(23):62-66.

Sartoratto A., Machado A.L.M., Delarmelina C., Figueira G.M., Duarte M.C.T. \& Rehder V.L.G. 2004. Composition and antimicrobial activity of essential oils from aromatic plants used in Brazil. Braz. J. Microbiol. 35(4):275-280. http://dx.doi.org/10.1590/S1517-83822004000300001.

Sartori L.C.A., Santos R.C. \& Marin J.M. 2012. Avaliação in vitro da eficácia de desinfetantes comerciais utilizados no pré e pós-diping frente à candida spp isolada de leite mastitico bovino. Ars Vet. Jaboticabal 28(4):240-243.

Schnitzler P., Nolkemper S., Stintzing F.C. \& Reichling J. 2008. Comparative in vitro study on the anti-herpetic effect of phytochemically characterized aqueous and ethanolic extracts of Salvia officinalis grown at two different locations. Phytomedicine 15(1/2):62-70. http://dx.doi.org/10.1016/j. phymed.2007.11.013. PMid:18068963.

Silva M.E.G.S., Guimarães A.L., Oliveira A.P., Araújo C.S., Siqueira Filho J.A., Fontana A.P., Damasceno P.K.F., Branco C.R.C., Branco A. \& Almeida J.R.G.S.
2012. HPLC-DAD analysis and antioxidant activity of Hymenaea martiana Hayne (Fabaceae). J. Chem. Pharm. Res. 4:1160-1166.

Thoria 0.O., Galal M.A., Ashour N.A. \& Hussain A.M. 2011. Treatment of experimentally induced mastitis in Nubian goats by Staphylococcus aureus using methanolic extract of Terminalia brownii leaves. J. Sci. Technol. 12:32-37.

Varo A., Mulero-Aparicio A., Adem M., Roca L.F., Raya-Ortega M.C., LópezEscudero F.J. \& Trapero A. 2017. Screening water extracts and essential oils from Mediterranean plants against Verticillium dahliae in olive. Crop Prot. 92:168-175. http://dx.doi.org/10.1016/j.cropro.2016.10.018.

Viegi L., Pieroni A., Guarrera P.M. \& Vangelisti R. 2003. A review of plants used in folk veterinary medicine in Italy as basis for a databank. J. Ethnopharmacol. 89(2/3):221-244. http://dx.doi.org/10.1016/j. jep.2003.08.003. PMid:14611886.

Wendlandt S., Feßler A.T., Monecke S., Ehricht R., Schwarz S. \& Kadlec K. 2013. The diversity of antimicrobial resistance genes among staphylococci of animal origin. Int. J. Med. Microbiol. 303(6/7):338-349. http://dx.doi. org/10.1016/j.ijmm.2013.02.006. PMid:23499306.

WHO 2008. Benefits and risks of the use of chlorine-containing disinfectants in food production and food processing: report of a joint FAO/WHO expert meeting. Ann Arbor, MI, USA. Disponível em <http://www.fao.org/ docrep/012/i1357e/i1357e.pdf> Acesso em 12 nov. 2015. 